\title{
Attenuation of exercise induced asthma by local hyperthermia
}

\author{
S L Johnston, D Perry, S O’Toole, Q A Summers, S T Holgate
}

\begin{abstract}
Background Prior treatment with local hyperthermia has been shown to prevent mast cell degranulation and leucocyte histamine release, and to reduce mortality and cellular infiltrates in a model of acute lung injury. Local hyperthermia is effective in reducing the symptoms of the common cold and perennial and seasonal allergic rhinitis, nasal patency also being improved in rhinitis. It is possible that these effects are mediated by common anti-inflammatory mechanisms, and that this treatment may be effective in the treatment of asthma. The effect of prior local hyperthermia on the response to exercise challenge and histamine bronchoprovocation was therefore examined. Methods In a randomised, double blind, placebo controlled, crossover study, 10 asthmatic subjects with exercise induced asthma used machines delivering 40 1/ minute of fully humidified air at either $42^{\circ} \mathrm{C}$ (active treatment) or $31^{\circ} \mathrm{C}$ (placebo treatment) for 30 minutes' tidal breathing. For each pretreatment, at two week intervals they underwent exercise challenges starting one and 24 hours after starting the inhalations. After a further two weeks the protocol was repeated with histamine substituted for the exercise challenges.
\end{abstract}

Results The mean (SE) maximum percentage fall in forced expiratory volume in one second $\left(F E V_{1}\right)$ was significantly lower one hour after treatment with air at $42^{\circ} \mathrm{C}(30 \cdot 8 \%(3 \cdot 1 \%))$ than after treatment with air at $31^{\circ} \mathrm{C}(22 \cdot 3 \%(2 \cdot 9 \%))$. There was no significant effect on exercise challenge at 24 hours, or on histamine challenge at either time point, though there were nonsignificant trends towards protection with exercise at 24 hours and with histamine at one hour.

Immunopharmacology Group, Medicine I, Southampton General Hospital, Southampton SO9 4XY

S L Johnston

D Perry

S O'Toole

Q A Summers

S T Holgate

Reprint requests to: Dr S L Johnston

Received 28 October 1991 Returned to authors 20 December 1991 Revised version received 7 February 1992

Accepted 27 February 1992 effective in relieving the symptoms of the common cold ${ }^{1-3}$ and of perennial ${ }^{34}$ and seasonal ${ }^{5}$ allergic rhinitis, where nasal patency is also improved. ${ }^{67}$ Allergic rhinitis and asthma have many features in common with respect to their inflammatory basis, and many of the symptoms of the common cold result from the release of inflammatory mediators. ${ }^{8}$ There is accumulating evidence to show that local hyperthermia interferes with inflammatory mechanisms by reducing mast cell degranulation and histamine release from leucocytes after IgE dependent challenge, ${ }^{9-12}$ reduces mortality and morbidity in an animal model of acute lung injury, ${ }^{13}$ enhances the anti-inflammatory effects of interferon, ${ }^{14-17}$ and reduces the mononuclear cell production of interleukins 1 and 2 and of granulocyte-macrophage colony stimulating factor and mononuclear cell natural killer activity, ${ }^{18}$ all of which are or represent cytokines active in the genesis of inflammation. Local hyperthermia also reduces the synthesis of normal cellular proteins, such as proinflammatory mediators and enzymes in the case of inflammatory cells, in favour of the production of heat shock proteins, ${ }^{19}$ whose functions are complex and ill understood but which themselves have important protective anti-inflammatory actions. ${ }^{2021}$

In view of these findings we hypothesised that local hyperthermia might have potential for the treatment of asthma. To investigate this we examined the effect of local hyperthermia, applied to the respiratory mucosa, on the response of asthmatic airways to challenge with exercise and histamine. We used exercise as an indirect stimulus to airway narrowing through mediator release, histamine being a direct stimulus acting via the $\mathrm{H}_{1}$ receptor. The heat was delivered to the respiratory mucosa in the form of preheated humidified air at $42^{\circ} \mathrm{C}$, and the study was controlled with a placebo machine delivering air at the temperature of the nasal mucosa $\left(31^{\circ} \mathrm{C}\right)$; the two machines were used on the subjects in a randomised double blind fashion.

\section{Methods}

SUBJECTS

Ten non-smoking asthmatic subjects (three male, seven female) aged 16-60 (mean age 38.1) years participated in the study. All had a history of exercise induced asthma. There were eight with atopic and two with non-atopic asthma as judged by at least one weal over $>3$ $\mathrm{mm}$ in diameter on skinprick testing with Dermatophagoides pteronyssinus, house dust, mixed grass pollens, and cat and dog dander (Bencard, Brentford, Middx). Inhaled bronchodilators were withheld for at least six hours before each challenge procedure, but inhaled corticosteroids were continued without inter- 


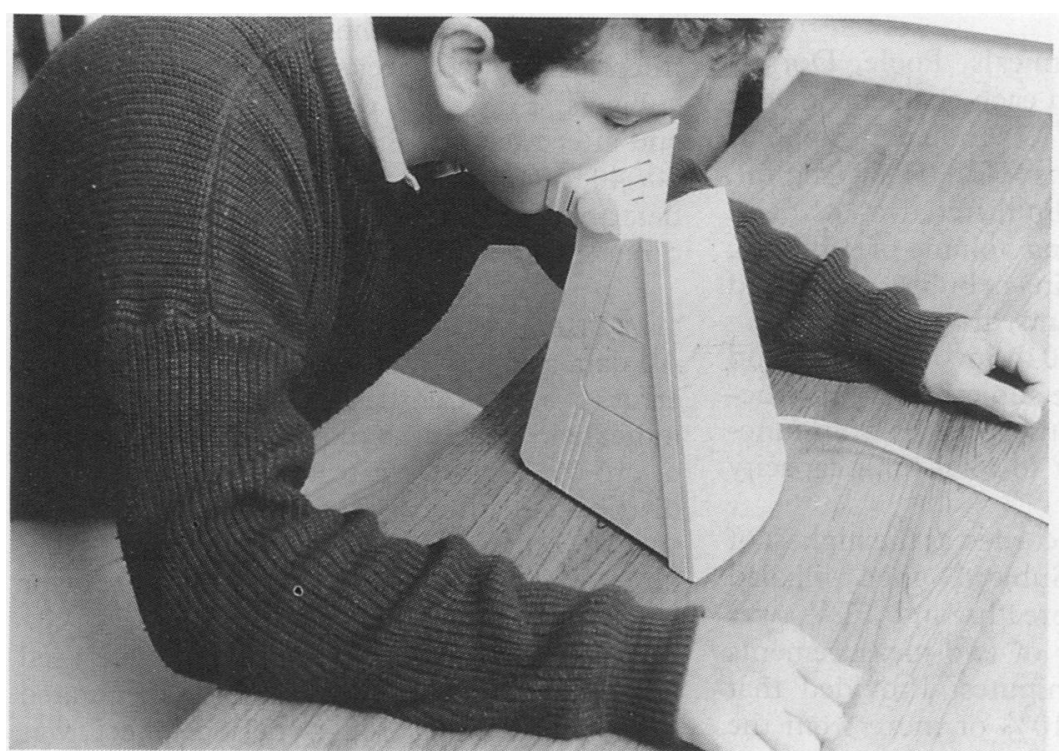

(A)

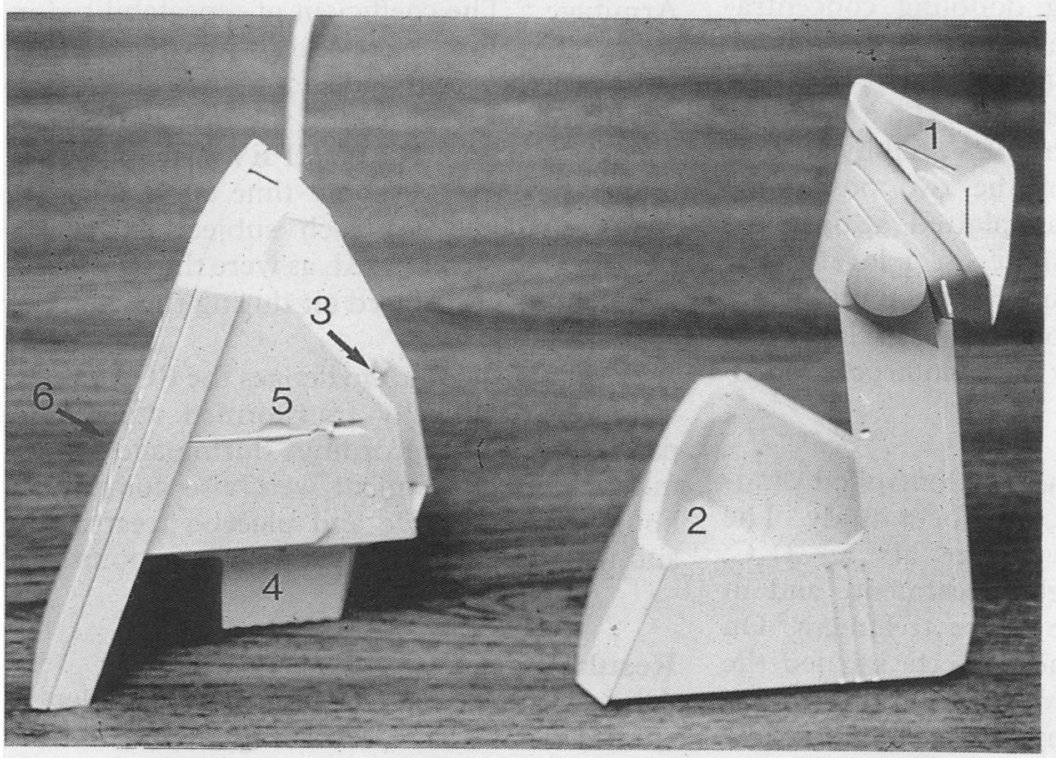

(B)

Figure 1 A-Subject having one of the study treatments. $B-A$ machine opened to show the internal features: (1) ventilated face mask; (2) water reservoir (filled to a line not visible); (3)

thermostat; (4) heating element; (5) body of machine containing fan, (6) air intake. CSchematic diagram representing the internal mechanisms of the machines used in the study.

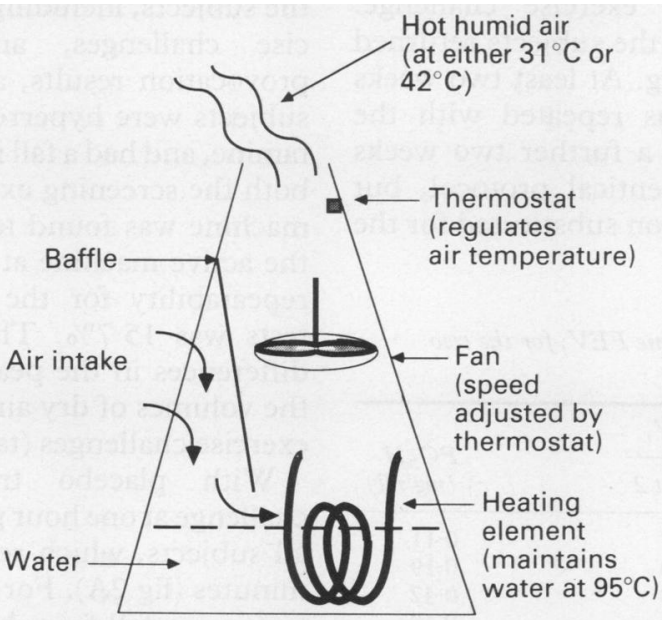

(C)

ruption; no subject was taking oral corticosteroids. All subjects were stable for at least four weeks before entry. Written informed consent was obtained from each subject and the study was approved by the Southampton University and hospitals ethical subcommittee.
LOCAL HYPERTHERMIA AND THE VIROTHERM MACHINES

Local hyperthermia was delivered by a device called Virotherm (patent pending; see fig 1), designed to expel fully saturated air, at $40 \mathrm{l} / \mathrm{min}$ through a ventilated face mask for normal tidal breathing. A thermostat was preset to deliver the air at specific temperatures. Two machines were used, one regulated to $42^{\circ} \mathrm{C}$ and the other to $31^{\circ} \mathrm{C}$. The temperature of the hot, humid air leaving the two machines was verified at the point of air entry into the face mask by an independent observer, who recorded the temperature every five minutes for 60 minutes, the results not being shown to the investigators until decoding had taken place.

The machines were identical in appearance, and were coded to render the study double blind. Blinding was effected by having an interval of two weeks between the treatments with the two machines, to make recall of the relative temperatures difficult, and by not informing subjects whether the hotter or the cooler temperature was expected to have beneficial effects. Decoding was carried out after full data collection.

\section{EXERCISE TESTING}

Subjects exercised on an electrically driven treadmill (PK Morgan Ltd, Chatham, Kent) while breathing dry air at room temperature and atmospheric pressure from a 200 litre Douglas bag, supplemented as necessary, via a mouthpiece connected to a two way valve and expired into the ambient air. The room temperature varied from $16^{\circ}$ to $25^{\circ} \mathrm{C}$ during the study. The volume of air inspired was measured with a Parkinson Cowan gas meter (PK Morgan Ltd) and the data were fed into a BBC microcomputer, which displayed the inspired volume in real time on a monitor. The total inspiratory volume and the peak heart rate over the six minutes of exercise were recorded. Forced expiratory volume in one second $\left(\mathrm{FEV}_{1}\right)$ was measured by the same dry wedge spirometer (Vitalograph, Buckingham) throughout, the higher of two consecutive readings being taken as the baseline value.

Before entering the study each volunteer undertook one to three trial six minute exercise tests on the treadmill until they were accustomed to the procedure. The gradient and speed of the treadmill were kept constant during each trial test, but were adjusted at the beginning of subsequent screening tests until a maximum fall in $\mathrm{FEV}_{1}$ from pre-exercise baseline levels of more than $20 \%$ was achieved on two occasions. Once an adequate exercise task had been established for each subject, the treadmill gradient and speed were kept constant for all subsequent challenges in that subject. On completion of each exercise challenge subjects had $\mathrm{FEV}_{1}$ measured at 1, 3, $5,10,15,20,25$, and 30 minutes, the higher value of two recordings at each time point being used. Each subject then repeated the task that produced the fall in $\mathrm{FEV}_{1}$ from baseline of more than $20 \%$ to assess reproducibility. 


\section{HISTAMINE CHALLENGE}

Histamine (BDH Chemicals, Poole, Dorset) was made up freshly on each challenge day in $0.9 \%$ sodium chloride to produce a range of doubling concentrations of $0.03-64 \mathrm{mg} / \mathrm{ml}$. The solutions were administered as aerosols generated from a starting volume of $3 \mathrm{ml}$ in a disposable Inspiron Mini-nebuliser (CR Bard International, Sunderland) driven by compressed air at a pressure of $20 \mathrm{lb} / \mathrm{in}^{2}(137.9 \mathrm{kPa})$, and at a rate of $8 \mathrm{l} / \mathrm{min}$. The subjects were instructed to take five consecutive breaths from functional residual capacity to total lung capacity via a mouthpiece. ${ }^{22}$

Baseline $\mathrm{FEV}_{1}$ was recorded as the highest of two measurements. Subjects then inhaled $0.9 \%$ saline for five breaths and $\mathrm{FEV}_{1}$ was recorded as the higher of two measurements after one and three minutes. Provided that $\mathrm{FEV}_{1}$ did not fall by $10 \%$ or more from the baseline value histamine provocation was undertaken. Increasing doubling concentrations of histamine were inhaled at five minute intervals and $\mathrm{FEV}_{1}$ was measured one and three minutes after each inhalation. The challenge was terminated when the $F E V_{1}$ fell by $20 \%$ or more of the higher of the two post-saline values. The $F E V_{1}$ was plotted against the concentration of histamine on a logarithmic scale; the provocative concentration producing a fall in $\mathrm{FEV}_{1}$ of $20 \%$ from the post-saline value $\left(\mathrm{PC}_{20} \mathrm{H}\right)$ was derived by linear interpolation.

\section{PROTOCOL}

The study was a placebo controlled, randomised, double blind, crossover study. The machine was set to deliver air at $31^{\circ} \mathrm{C}$, representing the placebo treatment, and at $42^{\circ} \mathrm{C}$, representing the active treatment. On each treatment visit the subjects inhaled the temperature conditioned humid air for $30 \mathrm{~min}$ utes, followed by a 30 minute interval to allow the airways to recover to normal temperature, before undergoing the exercise challenge. Twenty four hours later the subjects returned for repeat exercise testing. At least two weeks later this procedure was repeated with the second treatment. After a further two weeks subjects followed an identical protocol, but with histamine provocation substituted for the exercise challenge.

Table 1 Subjects' ages, maximum percentage fall from baseline $F E V_{1}$ for the two screening exercise tests, and the baseline $P C_{20}$ histamine

\begin{tabular}{|c|c|c|c|c|}
\hline \multirow[b]{2}{*}{ Subject No } & \multirow[b]{2}{*}{ Age (y) } & \multicolumn{2}{|c|}{ Max $\%$ fall in $F E V_{1}$} & \multirow{2}{*}{$\begin{array}{l}P C_{20} H \\
(m g / m l)\end{array}$} \\
\hline & & Visit 1 & Visit 2 & \\
\hline 1 & 51 & $44 \cdot 8$ & $50 \cdot 7$ & 0.11 \\
\hline 2 & 29 & $36 \cdot 8$ & $40 \cdot 0$ & $0 \cdot 19$ \\
\hline 3 & 32 & $29 \cdot 2$ & $28 \cdot 8$ & 0.42 \\
\hline 4 & 55 & $28 \cdot 6$ & $27 \cdot 9$ & 0.40 \\
\hline 5 & 34 & $24 \cdot 0$ & 27.5 & 1.74 \\
\hline 6 & 41 & $24 \cdot 3$ & 23.7 & 0.47 \\
\hline 7 & 33 & $27 \cdot 5$ & $34 \cdot 8$ & $0 \cdot 10$ \\
\hline 8 & 60 & $33 \cdot 3$ & $22 \cdot 6$ & 0.049 \\
\hline 9 & 16 & $33 \cdot 3$ & $35 \cdot 3$ & 0.04 \\
\hline 10 & 30 & $27 \cdot 7$ & $35 \cdot 0$ & 0.59 \\
\hline Mean & $38 \cdot 1$ & 31.9 & $32 \cdot 6$ & $0 \cdot 22^{\star}$ \\
\hline SEM & $4 \cdot 29$ & $2 \cdot 3$ & $2 \cdot 67$ & \\
\hline
\end{tabular}

* Geometric mean.

$\mathrm{PC}_{20} \mathrm{H}$-provocative dose of histamine causing a $20 \%$ fall in $\mathrm{FEV}_{1}$.
Finally, after a further two weeks, and with intervals of two weeks between treatments, subjects' $\mathrm{FEV}_{1}$ was recorded before, during, and after each 30 minute treatment $(5,10,20$, $30,40,50$, and 60 minutes after the start) to determine whether the heat treatment had any direct effect on airway calibre.

\section{STATISTICAL ANALYSIS}

All data are presented as means with standard errors in parèntheses unless otherwise indicated. The null hypothesis was rejected at $p<0.05$. Data were tested for normality of distribution (Statworks), and confirmed as such; comparisons between groups were therefore carried out with Student's $t$ test for paired data.

The order in which the machines were used was decided by allocating randomly generated numbers. Testing for a period effect was carried out by the method of Hills and Armitage. ${ }^{23}$ The coefficient of repeatability for the two screening exercise tests was determined by the method of Bland and Altman. ${ }^{24}$

For the exercise testing the maximum percentage fall from baseline $F E V_{1}$, and the area under the $\mathrm{FEV}_{1}$ response-time curve (AUC), were calculated for each subject and each treatment and compared, as were the heart rate and volume of inspired air during the exercise challenges.

For the histamine challenges the $\mathrm{PC}_{20}$ values were logarithmically transformed and compared; the $F E V_{1}$ recordings during and for 30 minutes after treatment were also compared, both between active and placebo treatments and with baseline $\mathrm{FEV}_{1}$, at each time point.

\section{Results}

All subjects completed both the challenge studies and the $\mathrm{FEV}_{1}$ recordings. There was no significant period effect. The baseline data for the subjects, including age, the screening exercise challenges, and baseline histamine provocation results, are given in table 1 . All subjects were hyperresponsive to inhaled histamine, and had a fall in $\mathrm{FEV}_{1}$ of at least $20 \%$ in both the screening exercise tests. The placebo machine was found to deliver air at $31^{\circ} \mathrm{C}$ and the active machine at $42^{\circ} \mathrm{C}$. The coefficient of repeatability for the two screening exercise tests was $15 \cdot 7 \%$. There were no significant differences in the peak heart rate achieved or the volumes of dry air inspired during the two exercise challenges (table 2 ).

With placebo treatment, the exercise challenge at one hour produced a fall in $\mathrm{FEV}_{1}$ in all subjects, which reached a maximum at 10 minutes (fig 2A). For the group as a whole the maximum fall from baseline $\mathrm{FEV}_{1}$ was $30.8 \%$ $(3.1 \%)$. The active treatment attenuated the exercise provoked fall in $\mathrm{FEV}_{1}$ at one hour in nine of the 10 subjects (fig 3), the maximum achieved for the group being a $22.3 \%(2.9 \%)$ fall from baseline, significantly less than after placebo $(p<0.02)$. In seven of the 10 subjects (fig 3 ) the protection extended to 24 hours, but for the group this just failed to reach statistical significance (maximum falls in $\mathrm{FEV}_{1} 28.8 \%$ 
Table 2 Mean peak heart rate (PHR) and mean of the total volume of dry air (TVDA) inspired during exercise testing for each machine at one and 24 hours for all 10 subjects

\begin{tabular}{lllll}
\hline & 1 h placebo & 24 h placebo & 1 h active & 24 h active \\
\hline PHR (/min) & 145 & 146.9 & 145.8 & 148 \\
TVDA (1) & 258.53 & 261.93 & 242.74 & 269.83
\end{tabular}

NS ${ }^{\star}$ for both peak heart rate and TVDA

$N S^{\star}$ for both peak heart rate and TVDA

^Student's paired $t$ test. inhaled $\beta_{2}$ agonists, ${ }^{38}$ which are known to be much more potent inhibitors of mast cell degranulation in addition to being functional antagonists. ${ }^{39}$ The mechanisms by which this treatment achieved its effect and the explanations for the size of the effect achieved are unknown, but there are several possibilities that might explain why only a partial effect occurred. Firstly, the method of heat delivery to the lower airway mucosa with the active treatment is likely to have been suboptimal, resulting in bronchial mucosal temperatures below the theoretically desired $43^{\circ} \mathrm{C}$. The aparatus was designed to increase the temperature of the nasal mucosa, which it does effectively, ${ }^{1}$ but efficient heat delivery to the lower airway is much more complex, and would be better achieved with a mouthpiece and a nose clip rather than the methods used in this perature at one hour (656 (94) for placebo and 436 (87) for active; $p<0.05$ ), but no significant difference at 24 hours (536 (97) for placebo and 440 (111) for active). All subjects were hyperresponsive to inhaled histamine with geometric mean $\mathrm{PC}_{20}$ values one and 24 hours after placebo treatment of $0 \cdot 1$ and $0 \cdot 17$ $\mathrm{mg} / \mathrm{ml}$ respectively. Application of the higher temperature had no significant effect on $\mathrm{PC}_{20}$ histamine at either time point after treatment (one hour 0.24 and 24 hours $0.19 \mathrm{mg} / \mathrm{ml}$; fig 4). There were no significant changes in $\mathrm{FEV}_{1}$, either from baseline or between the two treatments, at any time point during or for 30 minutes after each treatment (fig $2 \mathrm{C}$ ).

\section{Discussion}

Local hyperthermia significantly attenuates exercise induced asthma one hour after treatment and there is a non-significant trend towards protection at 24 hours. Peak heart rate and the volume of dry air inspired during each exercise test were not significantly different, suggesting that the treatment effect was not a result of differing work loads during exercise testing.

We chose exercise induced asthma as a reproducible means of inducing asthma, probably depending on release of inflammatory mediators and neural pathways. ${ }^{25}$ Although there is an alternative hypothesis that it depends on reactive hyperaemia induced by rapid rewarming after exercise induced cooling, $^{26}$ this hypothesis is controversial. ${ }^{27} \mathrm{We}$ consider that the weight of evidence is sufficient to implicate inflammatory mediator release, possibly via mast cell degranulation, ${ }^{28-31}$ the stimulus for release being an increase in the osmolality of the airway lining fluid rather than hypothermia and rebound vasodilatation. ${ }^{32} 33$ Published studies examining the role of leukotriene $\mathrm{D}_{4}$ and histamine in exercise induced asthma suggest an important role for these mediators as effectors of the constrictor response. ${ }^{34} 35$

The degree of protection against exercise induced asthma afforded by local hyperthermia after one hour is similar to that afforded by inhaled sodium cromoglycate ${ }^{36}$ and nedocromil sodium, ${ }^{37}$ but not as great as that afforded by
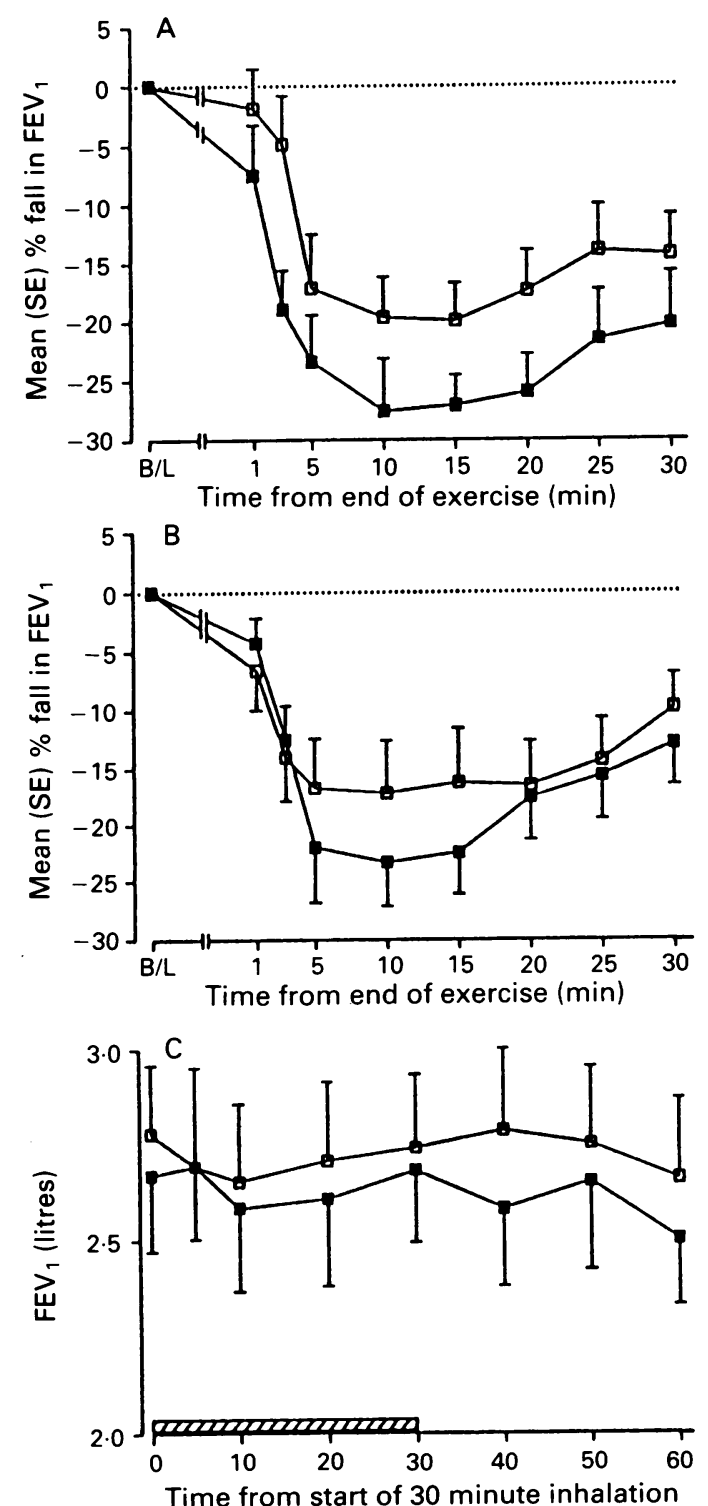

Figure 2 Effect of local hyperthermia treatment (open squares) and placebo (closed squares) on $A$-the FEV response to an exercise challenge one hour after treatment; $B$-the $F E V$, response to an exercise challenge 24 hours after treatment; $C$ - baseline airway calibre. $F E V$, was recorded during (hatched area) and for 30 minutes after each treatment. Each point represents the mean and the bars the SE for 10 subjects.

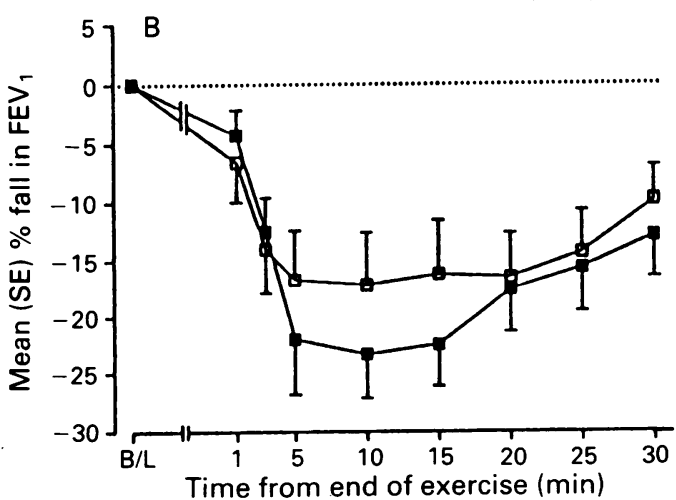




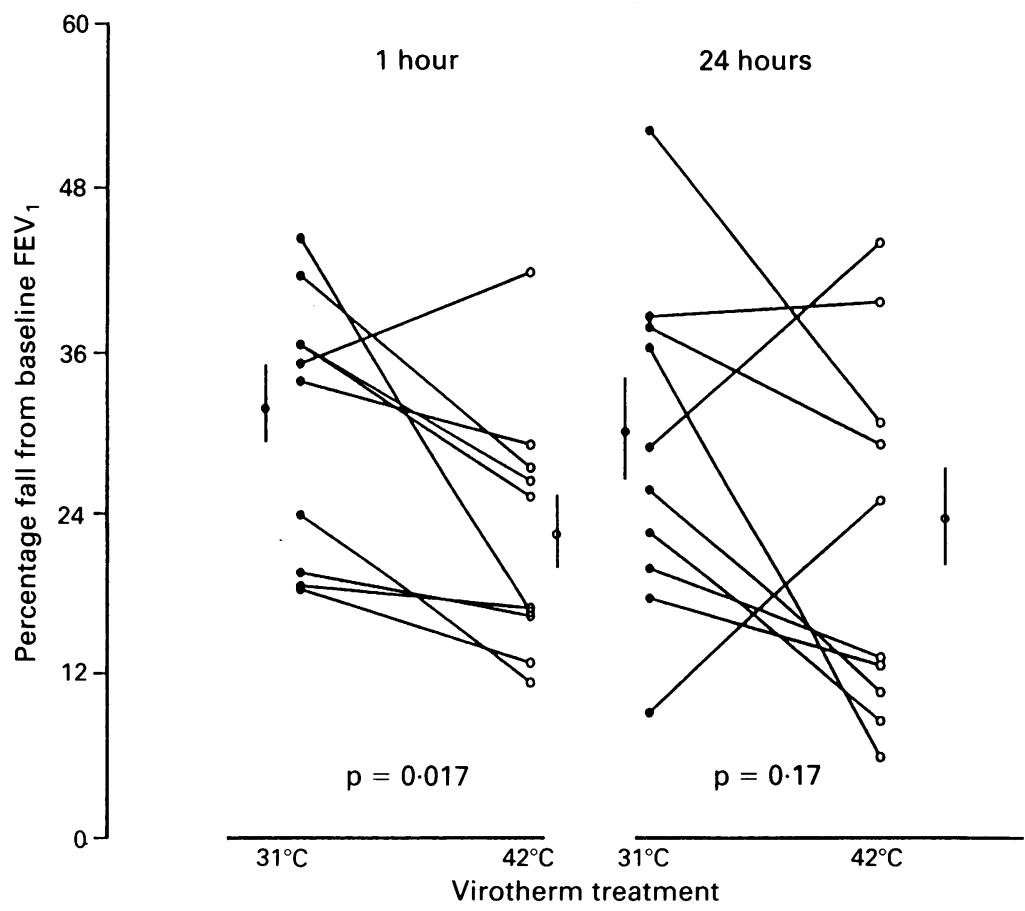

Figure 3 Individual plots of the maximum percentage falls from baseline $F E V$, during exercise challenge for the $42^{\circ} \mathrm{C}$ and $31^{\circ} \mathrm{C}$ treatments, with testing performed one and 24 hours after treatment. Open circles represent the active treatment and closed circles the placebo. Alongside are the corresponding circles and bars to representing the means and $S E$ (Student's paired t test used).

study, where no instructions were given with regard to nasal or mouth breathing. This was a preliminary study designed simply to look for a treatment effect and using commercially available equipment. Further studies on the optimal temperatures and modes of delivery of treatment are desirable. Secondly, local hyperthermia may interfere with some but not all of the mechanisms of mediator release from inflammatory cells in exercise induced asthma. Mast

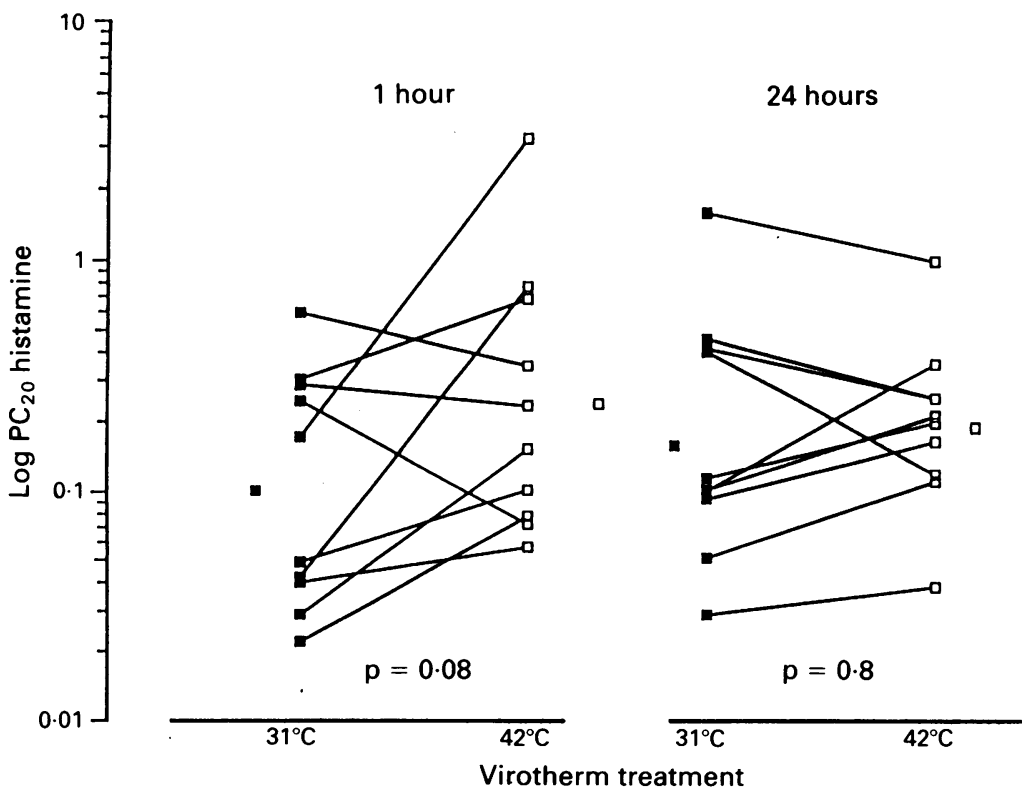

Figure 4 Individual plots on a logarithmic scale of the provocative concentration of histamine causing a $20 \%$ fall in $F E V_{1}\left(P C_{20}\right.$ histamine ) for the $42^{\circ} \mathrm{C}$ and $31^{\circ} \mathrm{C}$ treatments, with testing performed one and 24 hours after treatment. Open squares represent the active treatment, closed squares the placebo. Alongside are the corresponding squares representing the geometric means (Student's paired t test used on logarithmically transformed data). cells are known to release preformed mediators, such as histamine, by degranulation, whereas the products of arachidonic acid metabolism are newly synthesised on stimulation of the cell. The use of terfenadine, a histamine $\mathrm{H}_{1}$ receptor antagonist, and flurbiprofen, a cyclo-oxygenase inhibitor, in exercise induced asthma has suggested that histamine release may be maximal in the first five minutes of the response, whereas prostanoid release peaks later, around 15 minutes after exercise. ${ }^{40}$ Examination of the degree of separation of the curves in figures $2 \mathrm{~A}$ and $2 \mathrm{~B}$ suggests that one hour after treatment the greatest degree of protection afforded by local hyperthermia occurs within the first five minutes after exercise, at a time when histamine release is thought to be at its peak. ${ }^{40}$ In contrast, any protection that may be present 24 hours after the treatment is not apparent in the first five minutes but is most apparent between five and 20 minutes, when the products of arachidonic acid metabolism are at their most active. ${ }^{35} 40$

Finally, exercise induced asthma may be brought about by a combination of mechanisms, including both mediator release induced by osmotic change and reactive hyperaemia. The evidence outlined above $e^{9-12}$ would suggest that local hyperthermia might inhibit the former. Whether or not prior heating of the airway mucosa has an effect in reducing exercise induced vasoconstriction and as a consequence diminishes rebound vasodilatation is not known, but this seems unlikely in view of the 30 minute interval between the treatment and the exercise provoked airway cooling.

It is well established that inhalation of hypotonic aerosols may induce bronchoconstriction in asthmatic subjects. ${ }^{41}$ In the present study the quantity of water delivered to the airways was insufficient to cause any direct constrictor effect.

Histamine inhalation was used to examine the effects of thermal treatment on an index of non-specific airways responsiveness. In guinea pig airways experimental evidence suggests a reduction in smooth muscle contractility at higher than physiological temperatures. ${ }^{42}{ }^{43} \mathrm{In}$ the present study we failed to find any significant differences between the effects of active and placebo treatments on histamine responsiveness measured at either one or 24 hours, though there was a trend towards protection at one hour, which might have become statistically significant with larger numbers in the study. Such a small effect, however, is unlikely to be clinically significant.

In conclusion, we have shown that local hyperthermia reduces the severity of exercise induced asthma one hour after treatment. Further studies on the potential of local hyperthermia in the treatment of asthma and other inflammatory conditions, as well as the mechanisms of this protection, are warranted. We would like to thank the volunteers who kindly helped us with
this study, Dr J P Finnerty for his advice and helpful comments, this study, Dr J P Finnerty for his advice and helpful comments, Laboratories Ltd for financial support. 
1 Tyrrell D, Barrow I, Arthur J. Local hyperthermia benefits natural and experimental common colds. BMJ 1989; 298:1280-3.

2 Ophir D, Elad Y. Effects of steam inhalation on nasal patency and nasal symptoms in patients with the common cold. $\mathrm{Am}$ J Otolaryngol 1987;3:149-53.

3 Yerushalmi A, Lwoff A. Traitement du coryza infectieux et des rhinites persistantes allergiques par la thermotherapie. CR Acad Sci Paris 1980;291:957-9.

4 Yerushalmi A, Karman S, Lwoff A. Treatment of perennial allergic rhinitis by local hyperthermia. Proc Natl Acad $S c i$ USA 1982;79:4766-9.

5 Grossman J, Ball R, Shulan D, Porcella J. Treatment of seasonal allergic rhinitis with water vapour induced nasal hyperthermia [abstract]. J Allergy Clin Immunol 1988; 81:175.

6 Ophir D, Elad Y, Fink A, Fishler E, Marshak G. Effects of elevated intranasal temperature on subjective and objective findings in perennial rhinitis. Ann Otol Rhinol Laryngol 1988;97:259-63.

7 Ophir D, Elad Y, Dolev Z, Geller-Bernstein C. Effects of inhaled humidified warm air on nasal patency and nasal symptoms in allergic rhinitis. Ann Allergy 1988;60: 239-42.

8 Naclerio RM, Proud D, Kagey-Sobotka A, Lichtenstein LM, Hendley JO, Gwaltney JM. Is histamine responsible for the symptoms of rhinovirus colds? A look at the inflammatory mediators following infection. Pediatr Infect Dis J 1988;7:219-22.

9 Mongar JL, Schild HO. Effect of temperature on the anaphylactic reaction. $J$ Physiol 1957;135:320-30.

10 Mota I, Ishii T. Inhibition of mast cell disruption and histamine release in rat anaphylaxis in vitro. Comparison with compound 48/80. Br J Pharmacol 1960;15:82-7.

11 Chevance L-G, Ohayon H. Blocage par la chaleur de la degranulation des mastocytes de la muqueuse nasale du Cobaye. C R Acad Sci Paris 1983;296:499-500.

12 Middleton E Jr, Sherman WB, Fleming W, Van Arsdel PP $\mathrm{Jr}$. Some biochemical characteristics of allergic histamine release from leukocytes of ragweed-sensitive subjects. J Allergy 1960;31:448-54.

13 Villar J, Edelson J, Mullen JBM, Slutsky AS. Hyperthermia decreases mortality and lung injury in an animal model of acute lung injury [abstract]. Am Rev Respir Dis 1990; 141:A541.

14 Ron Y, Dougherty JP, Duff GW, Gershon RK. The effect of febrile temperatures on biological actions of interferons: abrogation of suppression of delayed-type hypersensitivity and antibody production. J Immunol 1984;133: 2037-42.

15 Downing JF, Taylor MW, Wei K-M, Elizondo RS. In vivo hyperthermia enhances plasma antiviral activity and stimulates peripheral lymphocytes for increased synthesis of interferon- - . J Interferon Res 1987;7:185-93.

16 Heron I, Berg K. The actions of interferons are potentiated at elevated temperature. Nature 1978;274:508-10.

17 Plaut $M$. Antigen-specific lymphokine secretory patterns in atopic disease. J Immunol 1990;144:4497-500.

18 Dinarello CA, Dempsey RA, Allegretta M, LoPreste G, Dainiak N, Parkinson DR, et al. Inhibitory effects of elevated temperature on human cytokine production and natural killer activity. Cancer Res 1986;46:6236-41.

19 Morimoto R, Fodor E. Cell-specific expression of heat shock proteins in chicken reticulocytes and lymphocytes. $J$ Cell Biol 1984;99:1316-23.

20 Kaufmann SHE. Heat shock proteins and the immune response. Immunol Today 1990;11:129-36.

21 Born W, Happ MP, Dallas A, Reardon C, Kubo R, Shinnick $\mathrm{T}$, et al. Recognition of heat shock proteins and $\gamma \dot{\delta}$ cell function. Immunol Today 1990;11:40-3.

22 Chai H, Farr RS, Froelich LA, Mathison DA, McLean JA,
Rosenthal RR. Standardisation of bronchial inhalation procedures. J Allergy Clin Immunol 1975;56:323-7.

23 Hills M, Armitage P. The two-period cross-over clinical trial. Br J Clin Pharmacol 1979;8:7-20.

24 Bland JM, Altman DG. Statistical methods for assessing agreement between two methods of clinical measurement. Lancet 1986; i:307-10.

25 Anderson SD, Daviskas E, Smith CM. Exercise-induced asthma: a difference in opinion regarding the stimulus. Allergy Proc 1989;10:215-26.

$26 \mathrm{McF}$ adden ER. Hypothesis: exercise-induced asthma as a vascular phenomenon. Lancet 1990;335:880-3.

27 Smith CM, Anderson SD, Walsh S, McElrea MS. An investigation of the effects of heat and water exchange in the recovery period after exercise in children with asthma. Am Rev Respir Dis 1989;140:598-605.

28 Hahn AG, Nogrady SG, Tumilty D McA, Lawrence SR, Morton AR. Histamine reactivity during the refractory period after exercise induced asthma. Thorax 1984; 39:919-23.

29 Lee TH, Nagy T, Nagakura T, Walport MJ, Kay AB. Identification and partial characterisation of an exerciseinduced neutrophil chemotactic factor in bronchial asthma. J Clin Invest 1982;69:889-99.

30 Lee TH, Nagakura T, Pagageorgiou N, Iikura Y, Kay AB. Exercise-induced late asthmatic reactions with neutrophil chemotactic activity. $N$ Engl J Med 1983;308:1502-5.

31 Lee TH, Assoufi BK, Kay AB. The link between exercise, respiratory heat exchange and the mast cell in bronchial asthma. Lancet 1983;i:520-2.

32 Hahn A, Anderson SD, Morton AR, Black JL, Fitch KD. A reinterpretation of the effect of temperature and water content of the inspired air in exercise-induced asthma. $\mathrm{Am}$ Rev Respir Dis 1984;130:575-9.

33 Rimmer J, Bryant DH. Effect of hypo- and hyper-osmolarity on basophil histamine release. Clin Allergy 1986;16: 221-30.

34 Israel E, Dermarkarian R, Rosenberg M, Sperling R, Taylor $G$, Rubin P, et al. The effects of a 5-lipoxygenase inhibitor on asthma induced by cold, dry air. N Engl J Med 1990; 323:1740-4.

35 Manning PJ, Watson RM, Margolskee DJ, Williams VC, Schwartz JI, O'Byrne PM. Inhibition of exercise-induced bronchoconstriction by MK-571, a potent leukotriene $D_{4}-$ receptor antagonist. $N$ Engl J Med 1990;323:1736-9.

36 Poppius H, Muitarri A, Kreus K-E, Korphonen O, Viljanen A. Exercise asthma and disodium cromoglycate. BMJ 1970;4:337-9.

37 Albazzaz MK, Neale MG, Patel KR. Dose-response study of nebulised nedocromil sodium in exercise induced asthma. Thorax 1989;44:816-9.

38 Godfrey S, Konig P. Inhibition of exercise-induced asthma by different pharmacological pathways. Thorax 1976; 31:137-43.

39 Church MK, Hiroi J. Inhibition of IgE-dependent histamine release from human dispersed lung mast cells by anti-allergic drugs and salbutamol. Br J Pharmacol 1987;90:421-9.

40 Finnerty JP, Holgate ST. Evidence for the roles of histamine and prostaglandins as mediators in exercise-induced asthma: the inhibitory effect of terfenadine and flurbiprofen alone and in combination. Eur Respir $J$ 1990;3:540-7.

41 Anderson SD, Schoeffel RE, Finney M. Evaluation of ultrasonically nebulised solutions for provocative testing in patients with asthma. Thorax 1983;38:284-91.

42 Souhrada JF, Presley D, Souhrada M. Mechanisms of the temperature effect on airway smooth muscle. Respir Phys 1983;53:225-37.

43 Souhrada M, Souhrada JF. The direct effect of temperature on airway smooth muscle. Respir Phys 1981;44:311-23. 